\title{
Luteolytic action of two antiprogestational agents (RU-38486 and ZK-98734) in the rat*
}

\author{
G. Singh, M. M. Singh, S. C. Maitra, W. Elger†, V. Kalra, S. N. Upadhyay, \\ S. R. Chowdhury and V. P. Kamboj
}

Central Drug Research Institute, Lucknow-226001, India, and $\uparrow$ Schering AG, Berlin, West Germany

\begin{abstract}
Summary. RU-38486 or ZK-98734 treatment ( $3 \mathrm{mg} /$ day, s.c.) to intact or hysterectomized adult female rats on Days 5-7 post coitum induced changes characteristic of luteolysis. Ultrastructurally, the luteal cells exhibited an extensive vacuolization of the cytoplasm and perinuclear areas, degeneration of mitochondrial cristae, massive accumulation of lipid droplets, increase in number of lysosome like granules and heterochromatinization of the nucleus. In general, RU-38486 induced more marked degeneration of the luteal cells than did ZK-98734. There was also a significant decrease in peripheral plasma progesterone concentrations in treated rats. We suggest that these antiprogestagens act via inhibition of luteal function in addition to their antagonism at the uterine progesterone receptor level.
\end{abstract}

Keywords: antiprogestagens; ultrastructure; corpora lutea; progesterone; rat

\section{Introduction}

The abortion-inducing property of the antiprogestagens RU-38486 and ZK-98734 is believed to be due to an inhibition of receptor-mediated progesterone action on the uterus (Philibert et al., 1982; Healy et al., 1983; J. M. R. Pongubala, personal communication). Attempts to elucidate action of these antiprogestagens on corpus luteum function by measuring plasma progesterone concentration have yielded equivocal results. Asch \& Rojas (1985) did not observe any difference in the plasma progesterone concentration in cyclic rhesus monkeys treated with RU-38486 during the luteal phase. In women, however, Kovacs et al. (1984) observed a dose-dependent decrease in plasma progesterone concentration and suggested a direct action of RU-38486 on luteal function. A similar decrease in plasma progesterone concentration in marmoset monkeys has been reported after treatment with ZK-98734 (S. D. Kholkute, personal communication). In view of these findings and the reported high affinity of RU-38486 to ovarian progesterone and glucocorticoid receptors (Schreiber et al., 1983), which have been suggested as having a role in ovarian morphology and hormone production (Schreiber \& Hsueh, 1979; Schreiber et al., 1982; Erickson, 1983; Hsueh et al., 1983), we undertook an ultrastructural study to determine changes in the luteal cells of rats treated with a contraceptive dose of these antiprogestagens (W. Elger, unpublished data).

\section{Materials and Methods}

Colony bred adult Sprague-Dawley rats $(200-250 \mathrm{~g})$ maintained at the institute in air-conditioned $\left(22 \pm 1^{\circ} \mathrm{C}\right)$ quarters and under uniform husbandry conditions were used. The animals were kept in groups of 10 and were given a pellet diet (Hind Levers Ltd, Bombay) and tap water ad libitum. Females were caged overnight with coeval males of

*Reprint requests to Dr V.P. Kamboj. 
proven fertility ( 1 male: 5 females) and were examined for the presence of spermatozoa in their vaginal smears on the following morning. The day of finding spermatozoa in the smear was taken as Day I of pregnancy.

In pilot studies, corpora lutea of rats treated with a contraceptive dose of RU-38486 (3 mg/day, s.c.) dissolved in castor oil:benzyl benzoate $(4: 1, \mathrm{v} / \mathrm{v})$ on Days 5-7 post coitum and autopsied on Day 9 showed ultrastructural changes characteristic of luteolysis. To rule out involvement of the uterine luteolytic factor in the absence of viable implantation sites in treated animals (W. Elger, unpublished), a group of mated rats was bilaterally hysterectomized on Day 2 post coitum, a procedure which is known to maintain luteal function for almost the duration of normal gestation (Silbiger \& Rothchild, 1963). Another group of mated rats was similarly sham operated. About $2 \mathrm{ml}$ sterile physiological saline $(0 \cdot 85 \%(\mathrm{w} / \mathrm{v}) \mathrm{NaCl}$ in glass-distilled water) were introduced into the peritoneal cavity of each rat before suturing to avoid adhesions.

At least 6 rats from each of the hysterectomized and the sham-operated groups were treated with RU-38486 or ZK98734 ( $3 \mathrm{mg} /$ day, s.c.) or the vehicle alone (castor oil:benzyl benzoate, 4:1, v/v) on Days 5-7 post coitum and killed by cervical dislocation on Days 9 or 12 post coitum. A group of rats treated with $6 \mathrm{mg}$ ZK-98734/day, s.c. on Days 5-7, was autopsied on Day 9 post coitum. Progesterone was assayed in the blood collected on Days 2, 5 and 9 post coitum: $100 \mu 1$ samples of plasma in duplicate were vortexed for $1 \mathrm{~min}$ with $5 \mathrm{ml}$ diethyl ether, the ether phase was decanted after freezing the aqueous phase in an instant freezer at $-50^{\circ} \mathrm{C}$ and left overnight at room temperature for evaporation to dryness. The residue was reconstituted in $2 \mathrm{ml}$ assay buffer $\left(3.05 \mathrm{~g} \mathrm{NaH}_{2} \mathrm{PO}_{4} .2 \mathrm{H}_{2} \mathrm{O}, 14.5 \mathrm{~g} \mathrm{Na}_{2} \mathrm{HPO}_{4}, 8.3 \mathrm{~g} \mathrm{NaCl}_{1} 1 \mathrm{~g} \mathrm{NaN}_{3}\right.$ and $1 \mathrm{~g}$ gelatin in one litre of glass-distilled water) and subjected to radioimmunoassay by the method and kit supplied by W.H.O., Geneva under their Matched Reagent Program and an LKB 1217 RACKBETA Liquid Scintillation Counter programmed for RIA. The assay is a conventional radioimmunoassay that utilizes dextran-charcoal for separation of free from antibody-bound hormone: $5 \mathrm{ml}$ diethyl ether in duplicate were similarly processed for assay blanks. The recovery of $\left[{ }^{3} \mathrm{H}\right]$ progesterone added to plasma was $>90 \%$. The sensitivity of the assay was $25 \mathrm{fmol} /$ tube when assaying $100 \mu \mathrm{l}$ plasma, and the intra- and inter-assay variations were within the normal range.

At autopsy, the uterus of each animal was examined for the presence of any implantation site(s). Both ovaries of each animal were carefully dissected out and the numbers of corpora lutea in each ovary were counted. The ovaries were then weighed to the nearest $2 \mathrm{mg}$ on a torsion balance and immediately fixed in chilled $3 \%$ glutaraldehyde: $2 \%$ paraformaldehyde fixative in $0.1 \mathrm{M}$-sodium cacodylate buffer ( $\mathrm{pH} 7 \cdot 3$ ) (Hoyer \& Bucana, 1982). After about $30 \mathrm{~min}$ at $4^{\circ} \mathrm{C}$, each ovary was cut into $2 \mathrm{~mm}^{3}$ pieces on dental wax under an AO Zoom stereomicroscope (model 561C-HI) while still immersed in the fixative and left in the fixative for a further period of $2.5 \mathrm{~h}$. The samples were then transferred to $0.1 \mathrm{M}$-sodium cacodylate buffer and stored at $4^{\circ} \mathrm{C}$ until further processing. Each sample was then osmicated in $1 \%$ osmium tetraoxide in $0.1 \mathrm{M}$-sodium cacodylate buffer $\left(\mathrm{pH} \mathrm{7.3)}\right.$ for $2 \mathrm{~h}$ at $4^{\circ} \mathrm{C}$, washed thoroughly in glass-distilled water, dehydrated in ascending gradations of acetone and were transferred to an acetone-plastic (Epon 812-Araldite 6005) mixture and were finally embedded in pure plastic mixture (Mollenhauer, 1964) in Beem capsules and kept in a moisture-free oven at $60^{\circ} \mathrm{C}$ for 18-20 h to polymerize. The blocks were carefully trimmed and initially $1 \mu \mathrm{m}$ thick sections were cut on an LKB Ultratome 8800 and stained with $1 \%$ aqueous toluidine blue in $1 \%$ sodium borate for localization of recent corpora lutea (Bruce et al., 1984) for ultrathin sectioning. The ultrathin sections $(40-60 \mathrm{~nm})$ were individually collected on clean 400 mesh grids, stained for $30 \mathrm{~min}$ with $1 \%$ uranyl acetate (Watson, 1958) and 5-10 min with lead citrate in a $\mathrm{CO}_{2}$-free atmosphere (Reynolds, 1963) and examined in a Philips EM 4 10LS electron microscope. Representative areas from each corpus luteum were photographed. Thick sections were photographed on a Carl Zeiss light microscope fitted with photography attachments. All chemicals for electron microscopic studies were purchased from Ernest $F$. Fullana Inc. (P.O. Box 444, Schenectady, NY 12301, U.S.A.), Sigma Chemical Company (P.O. Box 14508, St Louis, MO 63178, U.S.A.) and Ladd Research Industries Inc. (P.O. Box 1005, Burlington, VT 05402, U.S.A.).

\section{Results}

\section{Effect on pregnancy}

Subcutaneous administration of RU-38486 or ZK-98734 (3 mg/day) on Days 5-7 post coitum prevented pregnancy in all rats. All the treated animals had clear uteri and had no sign of implantation or resorption. In comparison, all the sham-operated vehicle-treated control rats became pregnant; none of the implantation sites showed any sign of resorption (Table 1).

\section{Effect on ovarian weight}

RU-38486 or ZK-98734 treatment induced a marked increase $(P<0.001)$ in weight of both the ovaries in sham-operated and hysterectomized rats, when compared to their corresponding vehicletreated groups. Both compounds induced an almost similar increase in weight of the ovaries in

Fig. 1. Light micrographs of corpora lutea of sham-operated rats: (a) Day 9, vehicle-treated; (b) Day 12, vehicle-treated; (c) Day 12, RU-38486-treated; (d) Day 12, ZK-98734-treated. Note hyalinization (arrow) of the corpora lutea in drug-treated rats. (a), (b) $\times 200$; (c), (d) $\times 80$; insets $\times 200$. 

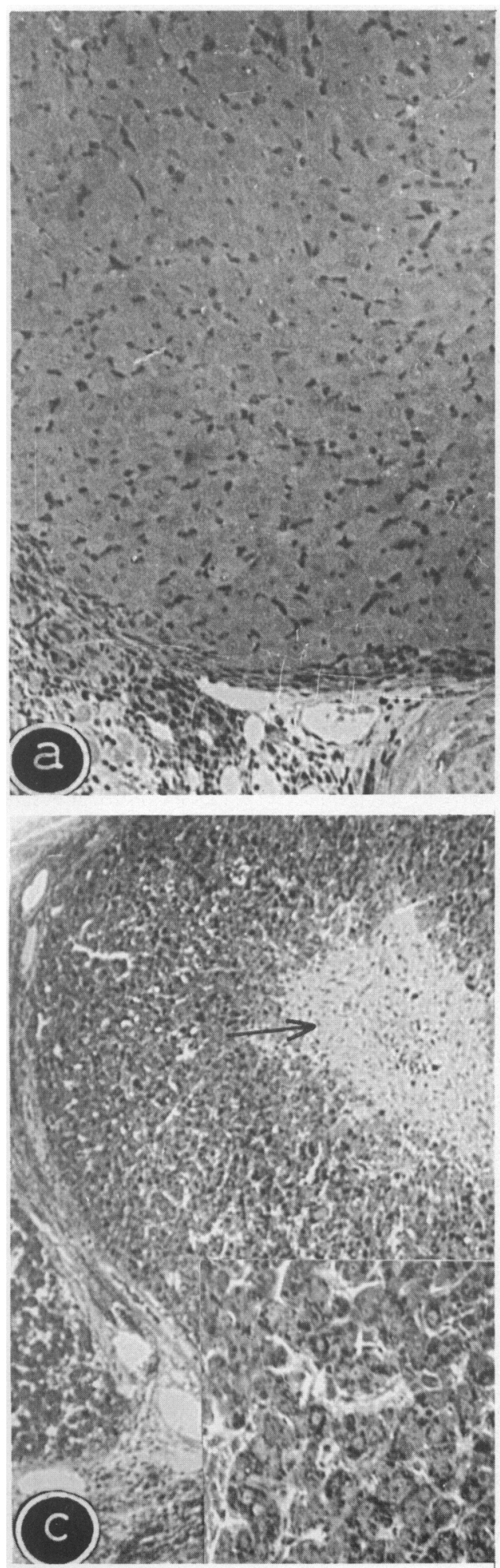
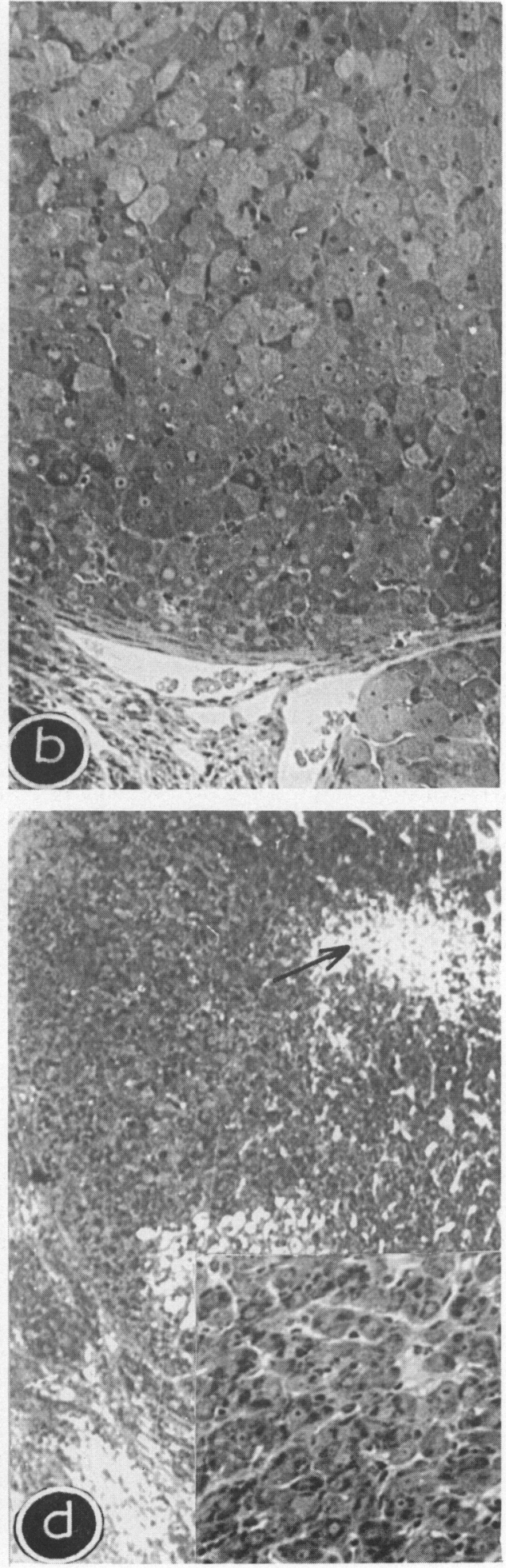

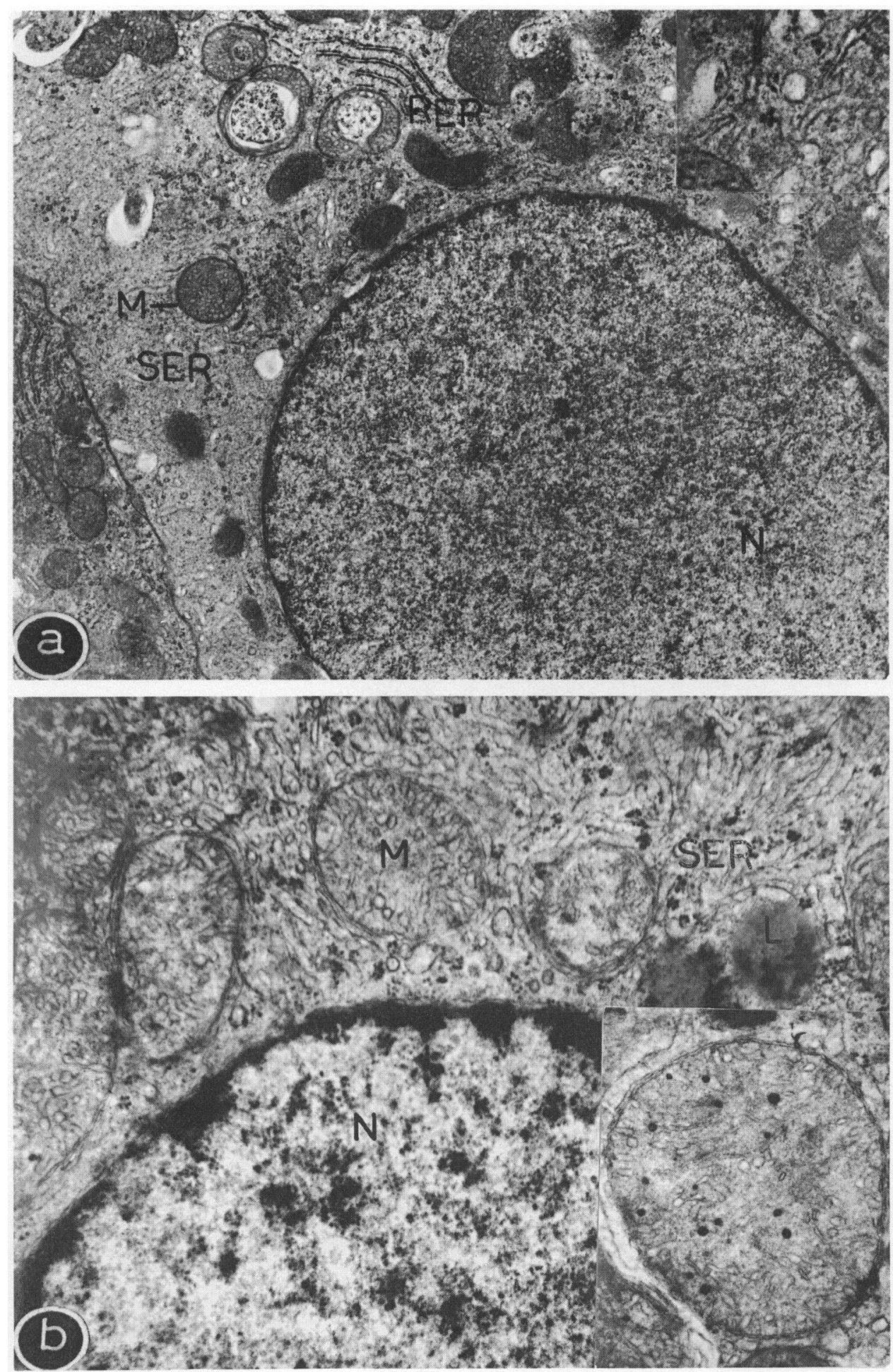
Table 1. Effect of RU-38486 and ZK-98734 on pregnancy, ovarian weight and plasma progesterone concentration in mated rats sham operated or hysterectomized on Day 2 post coitum

\begin{tabular}{|c|c|c|c|c|c|c|}
\hline & \multicolumn{3}{|c|}{ Sham operated } & \multicolumn{3}{|c|}{ Hysterectomized } \\
\hline & Vehicle & RU-38486 & ZK-98734 & Vehicle & RU-38486 & ZK-98734 \\
\hline \multicolumn{7}{|l|}{ No. of rats pregnant $\$$} \\
\hline Corpora lutea & $11 \cdot 1 \pm 1 \cdot 2$ & $11 \cdot 0 \pm 1 \cdot 0$ & $12.0 \pm 0.7$ & $10 \cdot 1 \pm 1 \cdot 2$ & $8.9 \pm 0.3$ & $10.7 \pm 0.8$ \\
\hline Implantations ${ }^{\dagger}$ & $8.9 \pm 1.7$ & Nil & $\overline{\mathrm{N}}_{\mathrm{il}}$ & 二- & - & - \\
\hline Ovarian wt (mg)† & $22 \cdot 6 \pm 1 \cdot 4$ & $34 \cdot 2 \pm 1 \cdot 6^{b}$ & $31 \cdot 6 \pm 1 \cdot 5^{b}$ & $21 \cdot 3 \pm 1 \cdot 3$ & $36 \cdot 2 \pm 2 \cdot 7^{b}$ & $35 \cdot 3 \pm 1 \cdot 8^{b}$ \\
\hline \multicolumn{7}{|l|}{$\begin{array}{l}\text { Progesterone conc. } \\
\text { (nmol/1) }\end{array}$} \\
\hline Day 2 & $97 \cdot 0 \pm 3.9$ & $100 \cdot 2 \pm 8 \cdot 5$ & $103.0 \pm 7.5$ & $104.9 \pm 1 \cdot 5$ & $104 \cdot 1 \pm 12 \cdot 6$ & $95 \cdot 8 \pm 6 \cdot 5$ \\
\hline Day 5 & $171 \cdot 1 \pm 22 \cdot 2^{\mathrm{c}}$ & $141.7 \pm 21.7$ & $169 \cdot 7 \pm 27 \cdot 0^{c}$ & $156 \cdot 1 \pm 14 \cdot 7^{\mathrm{c}}$ & $146.5 \pm 20 \cdot 2$ & $131 \cdot 1 \pm 3 \cdot 2^{\mathrm{d}}$ \\
\hline Day 9 & $215 \cdot 1 \pm 36 \cdot 1$ & $53 \cdot 6 \pm 1 \cdot 8^{\mathrm{b}, \mathrm{d}}$ & $62.8 \pm 6.0^{b . c}$ & $206 \cdot 3 \pm 30 \cdot 0$ & $64 \cdot 1 \pm 1 \cdot 7^{b \cdot c}$ & $67 \cdot 3 \pm 2 \cdot 7^{b, d}$ \\
\hline
\end{tabular}

Values are mean \pm s.e.m.

†Day 9 post coitum.

${ }^{\mathrm{B}} P<0.001$, versus corresponding vehicle treated groups.

${ }^{c} P<0.01,{ }^{d} P<0.001$, versus corresponding group of the preceding day post coitum. All other relevant comparisons were statistically insignificant.

sham-operated and hysterectomized animals. There was, however, no effect of hysterectomy on ovarian weight (Table 1). In general, the corpora lutea of rats treated with RU-38486 and ZK98734 appeared pale and lacked the prominence and lustre characteristic of mid-gestation corpora lutea.

\section{Effect on histology and ultrastructure of the corpora lutea}

The corpora lutea of sham-operated and hysterectomized vehicle-treated rats autopsied on Days 9 and 12 post coitum presented an almost similar picture. Under the light microscope, these consisted primarily of large nucleated polyhedral cells (Figs la, b). Ultrastructurally, the luteal cells on Day 9 contained an abundant smooth endoplasmic reticulum arranged in long tubular profiles and numerous pleomorphic mitochondria with villiform or lamellated cristae characteristic of steroidsynthesizing cells. A prominent Golgi complex, moderate amount of rough endoplasmic reticulum and polyribosomes were also present. The nuclei were generally large and round with dispersed euchromatin exhibiting a morphologically active state (Fig. 2a). The picture on Day 12 post coitum was virtually similar except that there was a marked increase in the amount and complexity of the smooth endoplasmic reticulum as well as the size of mitochondria. The matrix of some of the mitochondria contained small osmiophilic granules (Fig. 2b).

In comparison, the corpora lutea of rats treated with the contraceptive dose of RU-38486 or ZK-98734 showed changes characteristic of luteolysis (Adams \& Hertig, 1969; Koering \& Kirton, 1973; Balboni, 1976). The luteolytic effect was similar in the sham-operated and the hysterectomized animals. However, the cellular degeneration induced by RU-38486 appeared more marked than that induced by ZK-98734. The luteal cells of RU-38486-treated rats autopsied on Day 9 exhibited an

Fig. 2. Electron micrographs of luteal cells of vehicle-treated rats: (a) Day 9, hysterectomized, $\times 11000$; (b) Day 12, sham-operated, $\times 30000$. Note features characteristic of active steroidsynthesizing cells. Inset Fig. $2 \mathrm{a}(\times 30000)$ shows smooth endoplasmic reticulum $(\mathrm{SER})$. Some mitochondria (M) on Day 12 contain osmiophilic granules (inset Fig. 2b, × 44000 ). 

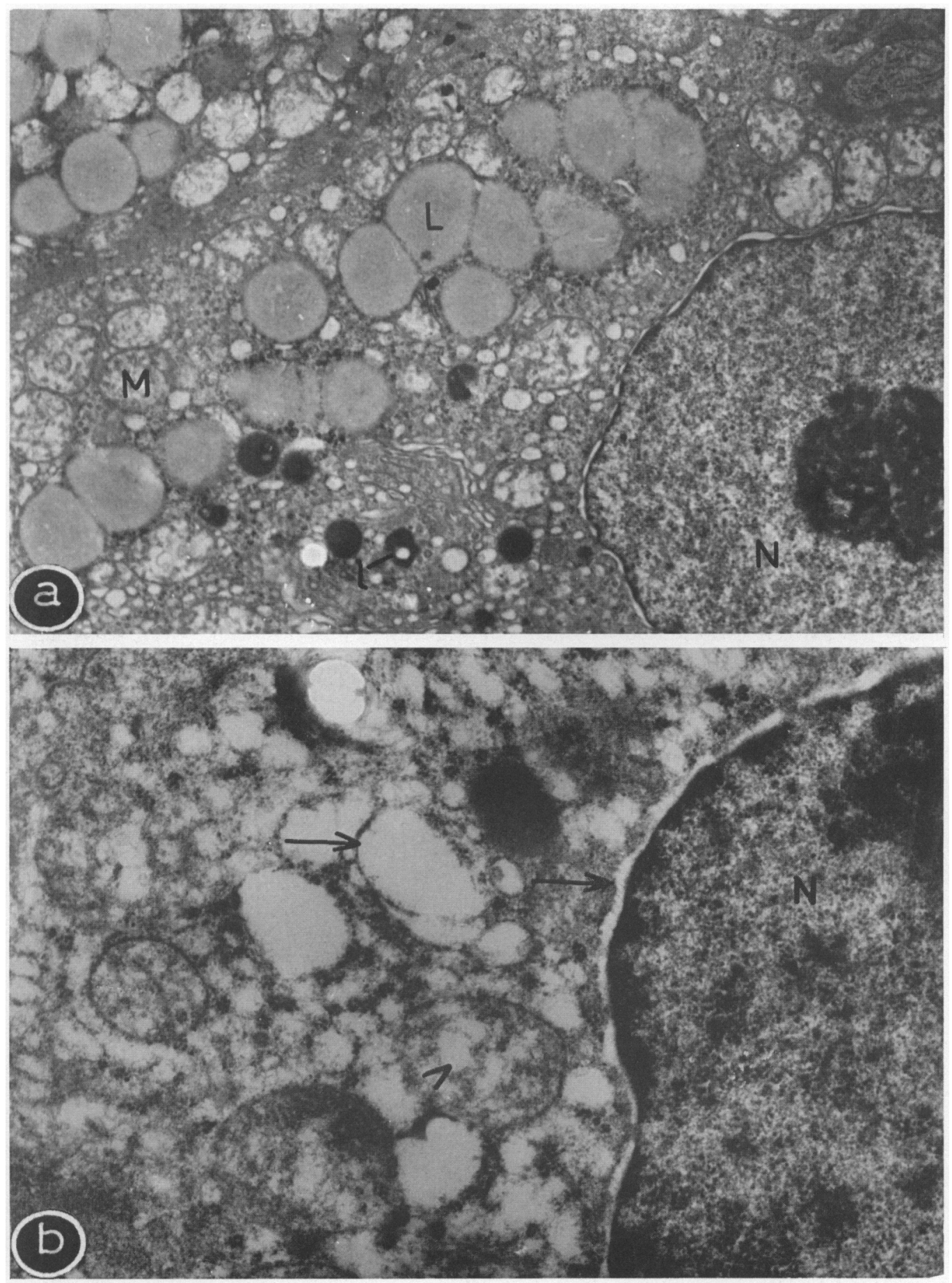

Fig. 3. Electron micrographs of luteal cells of hysterectomized RU-38486-treated rats: (a) Day 9, $\times 11000$; (b) Day 9, $\times 30000$. Note extensive vacuolization of the cytoplasm and perinuclear areas (arrow), accumulation of lipids ( $L$ ), degeneration of mitochondrial cristae (arrow head), appearance of lysosome-like granules (l) and heterochromatic nucleus (N). Polyribosomes are clearly seen at higher magnification. 

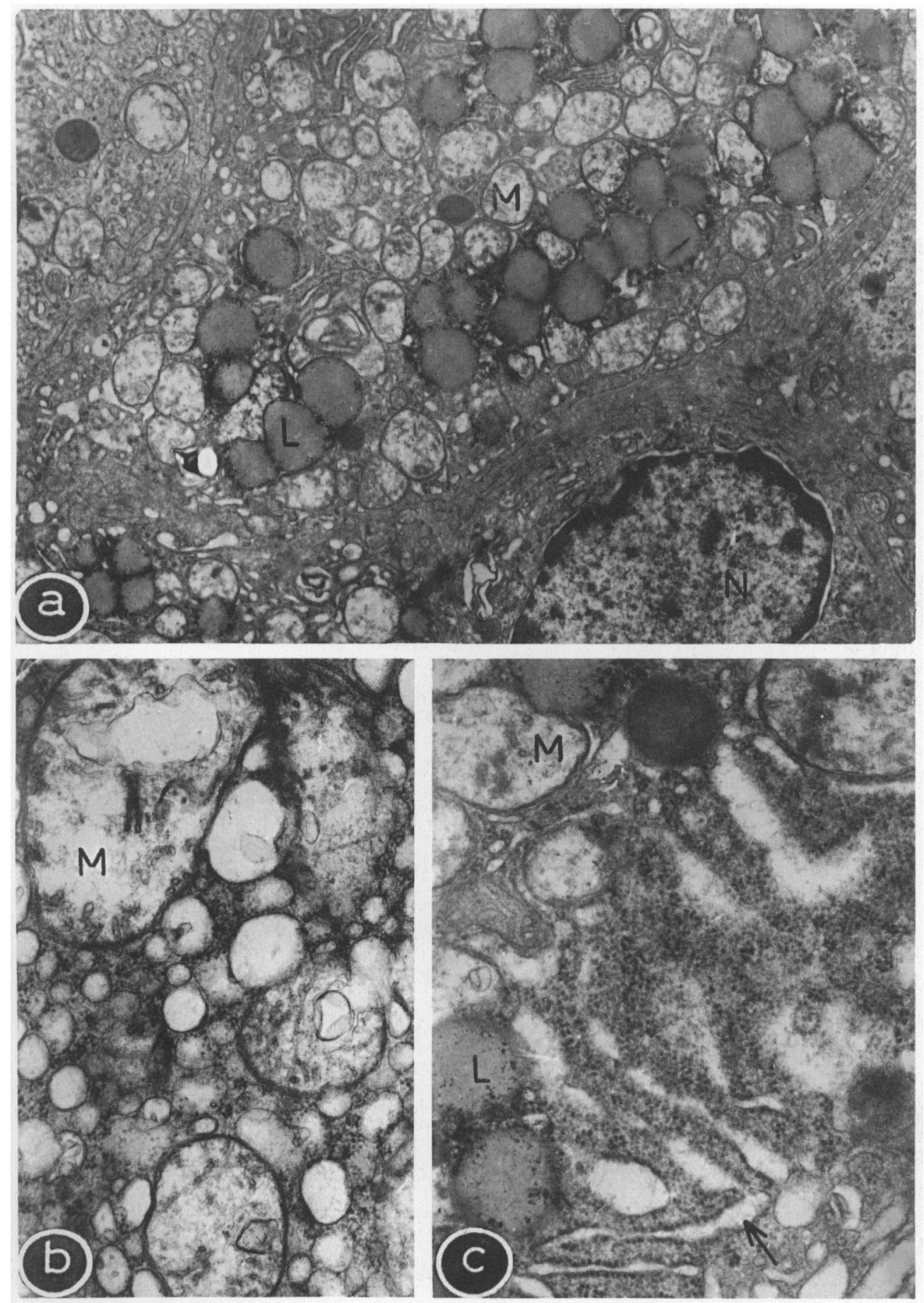

Fig. 4. Electron micrographs of luteal cells of ZK-98734-treated rats: (a) Day 9, hysterectomized, $\times 11000$; (b) \& (c) Day 9, sham-operated, $\times 30000$. Note cellular degeneration as in Fig. 3, except that the cytoplasmic vacuolization was limited to distention of the vesicles of endoplasmic reticulum while still retaining their identity (arrow). 

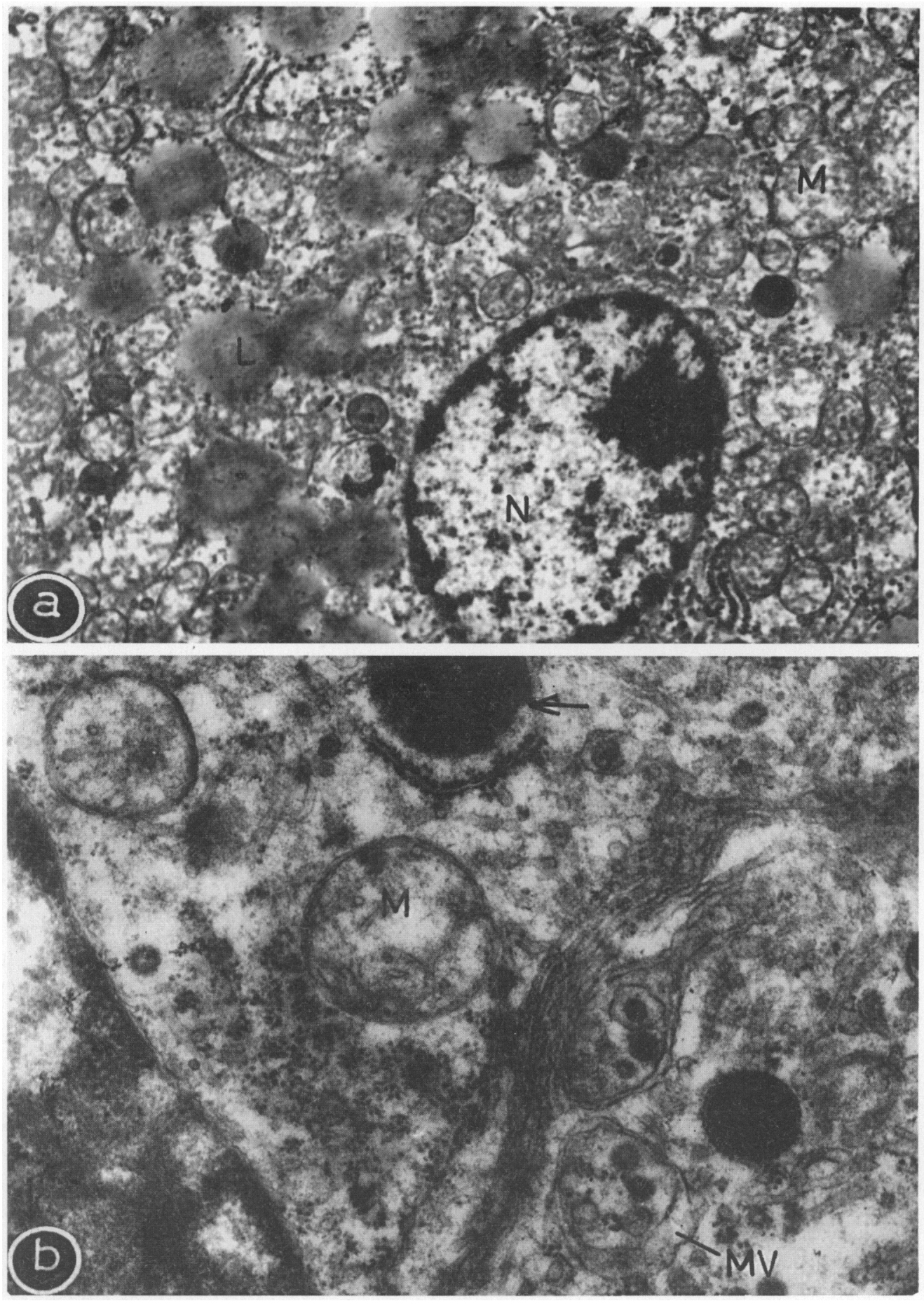

Fig. 5. Electron micrographs of luteal cells of sham-operated rats treated with $6 \mathrm{mg} Z \mathrm{ZK}-98734$ day: (a) Day 9, $\times 11$ 000; (b) Day 9, $\times 30000$. Note disorganization of the cytoplasm, appearance of multivesicular bodies (MV) and electron dense granules (arrow) which are more clearly seen at higher magnification. 
extensive vacuolization of cytoplasm due to distension and fragmentation of smooth endoplasmic reticulum. At places rough endoplasmic reticulum also appeared distended. There was a loss of the characteristic pleomorphism of the mitochondria which appeared more rounded in shape with degenerated cristae. Unlike controls, there was a marked accumulation of lipid droplets and appearance of lysosome-like granules. The nuclei presented an irregular heterochromatic appearance with perinuclear vacuolization (Figs 3a, b). In rats autopsied on Day 12 there was an extensive hyalinization (Parrott et al., 1986) of the corpora lutea (Fig. 1c). Ultrastructurally such corpora lutea contained only occasional luteal cells with a heterochromatic nucleus surrounded by a little cytoplasm. The degenerative changes induced by ZK-98734 were similar except that on Day 9 distended rough endoplasmic reticulum still retained its lamellated disposition and vacuolization of the cytoplasm was not as extensive as seen after RU-38486 treatment. Some mitochondria with myelinated figures were also observed (Figs 4a, b, c). On Day 12, there was a comparatively little hyalinization of the corpora lutea of rats treated with the contraceptive dose of this compound (Fig. 1d). However, in rats treated with double the contraceptive dose of ZK-98734, the luteal cell cytoplasm lost its integrity because of degeneration of subcellular organelles and the appearance of multivesicular bodies and electron-dense granules (Figs 5a, b).

\section{Effect on peripheral plasma progesterone concentration}

Progesterone concentration increased progressively between Days 2 and 9 post coitum in the sham-operated and hysterectomized vehicle-treated rats (Day 2 vs Days 5 or $9, P<0.001$, Table 1). RU-38486 or ZK-98734 treatment on Days 5-7 post coitum induced a marked decrease $(P<0.001$, Table 1$)$ in the plasma progesterone concentration on Day 9 post coitum in the shamoperated and the hysterectomized animals when compared to their corresponding vehicle-treated groups. Pretreatment values on Days 2 and 5 post coitum in the vehicle and the drug-treated groups of animals were almost similar $(P>0 \cdot 1)$.

\section{Discussion}

The results of this study clearly show that, at a contraceptive dose, RU-38486 or ZK-98734 administered subcutaneously to adult female rats on Days 5-7 post coitum induced changes characteristic of luteolysis (Adams \& Hertig, 1969; Koering \& Kirton, 1973; Balboni, 1976). In general, compound RU-38486 produced a more marked luteolytic effect than did ZK-98734. Both the compounds induced degeneration of mitochondrial cristae, massive accumulation of lipid droplets, appearance of lysosome-like granules and heterochromatinization of the nucleus in the luteal cells and a marked decrease in the peripheral plasma progesterone concentration. Compound RU-38486, in addition, produced extensive vacuolization of the cytoplasm and perinuclear areas which with ZK98734 was limited to distension of the vesicles of smooth and rough endoplasmic reticulum while still retaining their identity. Furthermore, RU-38486 produced a more severe degeneration of luteal cells which with ZK-98734 was observed only at double the contraceptive dose. Similar luteolytic changes have been observed in women with regressing corpora lutea during the cycle (Adams \& Hertig, 1969) and near parturition (Balboni, 1976) or in rabbits after treatment with an abortifacient dose of prostaglandin F-2 $\alpha$ (Koering \& Kirton, 1973). While a similar decrease in peripheral plasma progesterone concentration has been observed in women (Kovacs et al., 1984) and marmosets (S. D. Kholkute, personal communication) treated with abortifacient doses of RU-38486 and ZK98734 respectively, no other information is so far available on the effect of these agents at the ovarian level. In comparison, the luteal cells of vehicle-treated sham-operated and hysterectomized rats on Days 9 and 12 post coitum have been reported to exhibit features characteristic of active steroid-secreting cells and have abundant smooth endoplasmic reticulum arranged in long tubular profiles, moderate rough endoplasmic reticulum and polyribosomes, numerous pleomorphic 
mitochondria with villiform or lamellated cristae and large round nuclei with dispersed euchromatin (Enders, 1973; Long, 1973). At Day 12 post coitum, some of the mitochondria contain small osmiophilic granules. Similar dark granules have been observed in normal mitochondria of luteal (Adams \& Hertig, 1969) as well as non-luteal tissues (Haggis, 1966). The exact composition or function of these granules is, however, not known.

The luteolytic effect of these antiprogestagens appears to be due to their direct action on the corpora lutea, since ovarian granulosa cells of rats, like those of other mammals, are known to contain receptors for progesterone and glucocorticoids (Louvet et al., 1977; Schreiber \& Hsueh, 1979; Schreiber et al., 1982) and one of these compounds (RU-38486) has been shown to bind to these receptors with very high affinity (Schreiber et al., 1983). The present findings also confirm the regulatory role of receptor-mediated action of progesterone and glucocorticoids on ovarian progesterone production as has been demonstrated earlier by a number of studies (Erickson, 1983; Hsueh et al., 1983).

The luteolytic action of these agents does not appear to be mediated via production of the uterine luteolytic factor, PGF-2 $\alpha$ (Pharris \& Wyngarden, 1969), in the absence of any viable implantation sites in the uteri of treated rats, since in the present studies almost similar degenerative changes in the corpora lutea and a decrease in peripheral plasma progesterone concentration were observed in treated rats hysterectomized on Day 2 of pregnancy, thereby eliminating the source of luteolysin, which normally extends the functional life of corpora lutea to almost the length of gestation (Silbiger \& Rothchild, 1963). It is, however, not known whether these agents have any effect on secretion of pituitary $\mathrm{LH}$ and prolactin or responsiveness of the ovaries to these luteotrophins, which are required for the first 12 days of pregnancy for sustained progesterone release from the corpora lutea, after which the placenta is known to secrete the luteotrophic complex (Lamprecht et al., 1969; Hilliard, 1973).

Previous studies have demonstrated a decrease in size of the corpora lutea undergoing regression (Blatchley \& Donovan, 1969; Pharris, 1970). In the present study, treatment with antiprogestagens produced a significant increase in the overall weight of the ovaries. Although we did not measure size or weight of the individual corpora lutea, the observed increase in weight of the ovaries does not appear to be due to functional corpora lutea which appeared pale and lacked the prominence and lustre characteristic of mid-gestation.

Since these compounds are being clinically evaluated for early abortifacient and mensesregulating activity when ovarian support is essential in almost all mammals, including primates (Csapo \& Pulkkinen, 1978), it is inferred that these agents might induce these effects via suppression of ovarian function in addition to their antagonism of receptor-mediated progesterone action on the uterus.

We thank Dr M. M. Dhar, Director, for his interest in the study; the Ministry of Health and Family Welfare, Government of India for financial assistance; the Special Programme of Research, Development and Research Training in Human Reproduction, W.H.O. Geneva, for supply of reagents for RIA of steroids under their Matched Reagent Program; and Mrs A. Thomas and Miss T. S. Kunjumol for typing the manuscript. G.S. is a CSIR Junior Research Fellow. CDRI Communication No. 4059.

\section{References}

Adams, E.C. \& Hertig, A.T. (1969) Studies on the human corpus luteum. I. Observations on the ultrastructure of development and regression of the luteal cells during the menstrual cycle. J. Cell Biol. 41, 696-715.

Asch, R.H. \& Rojas, F.J. (1985) The effects of RU 486 on the luteal phase of the rhesus monkey. J. Steroid Biochem. 22, 227-230.
Balboni, G.C. (1976) Histology of the ovary. In The Endocrine Function of the Human Ovary, pp. 1-24. Eds V.H.T. James, M. Serio \& G. Guisti. Academic Press Inc., London.

Blatchley, F.R. \& Donovan, B.T. (1969) Luteolytic effect of prostaglandin in the guinea pig. Nature, Lond. 221, 1065-1066. 
Bruce, N.W., Meyer, G.T. \& Dharmarajan, A.M. (1984) Rate of blood flow and growth of the corpora lutea of pregnancy and previous cycles throughout the pregnancy in rats. J. Reprod. Fert. 71, 445-452.

Csapo, A.I. \& Pulkkinen, M. (1978) Indispensability of the human corpus luteum in the maintenance of early pregnancy: lutectomy evidence. Obstet. Gynecol. Surv. 33, 69-81.

Enders, A.C. (1973) Cytology of corpus luteum. Biol. Reprod. 8, 158-182.

Erickson, G.F. (1983) Primary cultures of ovarian cells in serum free medium as models of hormonedependent differentiation. Molec. cell. Endocrinol. 29, $21-49$.

Haggis, G.H. (1966) Abnormal structures in mitochondria. In The Electron Microscope in Molecular Biology, pp. 41-43. Longmans Green \& Co. Ltd, London.

Healy, D.L.. Baulieu, E.E. \& Hodgen, G.D. (1983) Induction of menstruation by an antiprogesterone steroid (RU 486) in primates: site of action, dose-response relationships and hormonal effects. Fert. Steril. 40, 253-257.

Hilliard, J. (1973) Corpus luteum function in guinea pigs, hamsters, rats, mice and rabbits. Biol. Reprod. $\mathbf{8}$, 203-221.

Hoyer, L.C. \& Bucana, C. (1982) Principles of immunoelectron microscopy. In Antibody as a Tool-The Application of Immunocytochemistry, pp. 233-271. Eds J.J. Marchalanois \& G.W. Wair. John Wiley, London.

Hsueh, A.J.W., Jones, P.B.C., Adashi, E.Y., Wang, C., Zhuang, L.Z. \& Welsh, T.W. (1983) Intraovarian mechanisms in the hormonal control of granulosa cell differentiation in rats. J. Reprod. Fert. 69, 325-342.

Koering, M.J. \& Kirton, K.T. (1973) The effect of prostaglandin $F_{2 a}$ on the structure and function of the rabbit ovary. Biol. Reprod. 9, 226-245.

Kovacs, L., Sas, M., Resch, B.A., Ugocsai, G., Swahn, M.L., Bygdeman, M. \& Rowe, P.J. (1984) Termination of very early pregnancy by RU 486 -an antiprogestational compound. Contraception 29, $399-410$.

Lamprecht, S.A., Lindner, H.R. \& Strauss, J.F. (1969) Induction of $20 \alpha$-hydroxysteroid dehydrogenase in rat corpora lutea by pharmacological blockade of pituitary prolactin secretion. Biochim. Biophys. Acta 187, 133-143.

Long, J.A. (1973) Corpus luteum of pregnant rat. Biol. Reprod. 8, 87-99.

Louvet, J.P., Baislic, M., Bayard, F. \& Boulard, C. (1977) Glucocorticoid receptors in rat ovarian granulosa cell cytosol. Endocrinology 100, Suppl., Abstr. 601.

Mollenhauer, H.H. (1964) Plastic embedding mixture for use in electron microscope. Stain Technol.39, 111-114.

Parrott, N.R., Sunter, J.P., Taylor, R.M.R. \& Johnston, D.A. (1986) Gastric hyalinization presenting in life and mimicking gastric cancer. Arch. Pathol. Lab. Med. 110, 155-156.

Pharris, B.B. (1970) The possible vascular regulation of luteal function. Persp. Biol. Med. 13, 434-444.

Pharris, B.B. \& Wyngarden, L.J. (1969) The effect of prostaglandin $\mathbf{F}_{2 a}$ on the progesterone content of ovaries from pseudopregnant rats. Proc. Soc. exp. Biol. Med. 130, 92-94.

Philibert, D., Deraedt, R., Tournemine, C., Mary, I. \& Teutch, G. (1982) RU 38486-a potent antiprogesterone. J. Steroid. Biochem. 17, lxviii, Abstr. 204.

Reynolds, E.S. (1963) The use of lead citrate at high $\mathrm{pH}$ as an electron opaque stain in electron microscopy. $J$. Cell Biol. 17, 208-212.

Schreiber, J.R. \& Hsueh, A.J.W. (1979) Progesterone receptor in rat ovary. Endocrinology 105, 915-919.

Schreiber, J.R., Nakamura, K. \& Erickson, G.F. (1982) Rat ovary glucocorticoid receptor: identification and characterization. Steroids 39, 569-584.

Schreiber, J.R., Hsueh, A.J.W. \& Baulieu, E.E. (1983) Binding of the antiprogestin RU-486 to rat ovary steroid receptors. Contraception 28, 77-85.

Silbiger, M. \& Rothchild, I. (1963) The influence of the uterus on corpus luteum-pituitary relationship in the rat. Acta endocr., Copenh. 43, 521-538.

Watson, M.L. (1958) Staining of tissue sections for electron microscopy with heavy metal. J. Biophys. Biochem. Cytol. , 475-478.

Received 2 June 1987 